\title{
Vibrational dynamics of fullerene molecules adsorbed on metal surfaces: a synchrotron infrared study
}

Petra Rudolf, Laboratoire Interdisciplinaire de Spectroscopie Electronique

Facultes Universitaires Notre-Dame de la Paix, 61 Rue de Bruxelles, B-5000 Namur, Belgium

Rasmita Raval

Leverhulme Centre and IRC in Surface Science, Dept. of Chemistry, University of Liverpool, Liverpool L69 3BX, United Kingdom

P. Dumas

LURE, Centre Universitaire Paris-Sud

BP 34, F91898-Orsay Cédex, France

G. P. Williams

National Synchrotron Light Source

Brookhaven National Laboratory

Upton, New York, USA 11973, USA

July 1999

National Synchrotron Light Source

Brookhaven National Laboratory

Operated by

Brookhaven Science Associates

Upton, NY 11973

Under Contract with the United States Department of Energy

Contract Number DE-AC02-98CH10886 


\section{DISCLAIMER}

This report was prepared as an account of work sponsored by an agency of the United States Government. Neither the United States Government nor any agency thereof, nor any of their employees, nor any of their contractors, subcontractors or their employees, makes any warranty, express or implied, or assumes any legal liability or responsibility for the accuracy, completeness, or any third party's use or the results of such use of any information, apparatus, product, or process disclosed, or represents that its use would not infringe privately owned rights. Reference herein to any specific commercial product, process, or service by trade name, trademark, manufacturer, or otherwise, does not necessarily constitute or imply its endorsement, recommendation, or favoring by the United States Government or any agency thereof or its contractors or subcontractors. The views and opinions of authors expressed herein do not necessarily state or reflect those of the United States Government or any agency thereof. 


\section{DISCLAIMER}

Portions of this document may be illegible in electronic image products. Images are produced from the best available original document. 


\title{
Vibrational dynamics of fullerene molecules adsorbed on metal surfaces : a synchrotron infrared study
}

\author{
Petra Rudolf ${ }^{a}$, Rasmita Raval ${ }^{b}$, Paul Dumas ${ }^{c}$ and Gwyn P. Williams ${ }^{d}$ \\ ${ }^{a}$ Laboratoire Interdisciplinaire de Spectroscopie Electronique, Facultés Universitaires Notre-Dame de \\ la Paix, 61 Rue de Bruxelles, B-5000 Namur, Belgium \\ ${ }^{d}$ Leverhulme Centre and IRC in Surface Science, Dept. of Chemistry, University of Liverpool, \\ Liverpool L69 3BX, United Kingdom \\ ${ }^{c}$ LURE, Centre Universitaire Paris-Sud, BP 34, F 91898 Orsay Cedex- France. \\ ${ }^{d}$ National Synchrotron Light Source, Brookhaven National Laboratory, Upton, NY 11973, USA
}

\begin{abstract}
Infrared spectroscopy of chemisorbed $\mathrm{C}_{60}$ on $\mathrm{Ag}(111), \mathrm{Au}(110)$ and $\mathrm{Cu}(100)$ reveals that a non-IR active mode becomes active upon adsorption and that its frequency shifts proportionally with the charge transferred from the metal to the molecule by about $5 \mathrm{~cm}^{-1}$ per electron. The temperature dependence of the frequency and the width of this IR feature has also been followed for $\mathrm{C}_{60} / \mathrm{Cu}(100)$ and was found to agree well with a weak anharmonic coupling (dephasing) to a low frequency mode which we suggest to be the frustrated translational mode of the adsorbed molecules.

Additionally the adsorption is accompanied by a broadband reflectance change which is interpreted as due to the scattering of conduction electrons of the metal surface by the adsorbate. The reflectance change allows to determine the friction coefficient of the $\mathrm{C}_{60}$ molecules which results to be rather small $\left(\sim 2 \times 10^{9} \mathrm{~s}^{-1}\right.$ for $\mathrm{Ag}$ and $\mathrm{Au}$, and $\sim 1.6 \times 10^{9} \mathrm{~s}^{-1}$ for $\left.\mathrm{Cu}\right)$, consistent with a marked metallic character of the adsorbed molecules.

Pre-dosing of alkali atoms onto the metal substrates drastically changes the infrared spectra recorded during subsequent $\mathrm{C}_{60}$ deposition: antiabsorption bands, as well as an increase of the broadband reflectance occur and are interpreted as due to strong electron-phonon coupling with induced surface states.
\end{abstract}

Keywords: $\quad$ Infrared reflectance, fullerenes, synchrotron infrared, friction, surface.

\section{INTRODUCTION}

Electron-phonon coupling plays an important role in determining the physical properties of fullerene-based materials, its most important manifestation being the superconductivity exhibited by fullerides $\left(A_{X} C_{60}, A=\right.$ alkali or alkaline earth metal) at transition temperatures only exceeded by those of the cuprates. Not all of the $A_{x} C_{60}$ salts are superconductors, they can also be are either semiconductors or metals and present a variety of crystallographic phases, depending on the concentration and the type of metal atoms used to form the compound. ${ }^{1}$ Electron-phonon coupling does not only determine the transport properties of these materials it also has a strong impact on the vibrational spectra, as was first found by Fu et al. who discovered the giant vibrational resonances in $\mathrm{K}_{6} \mathrm{C}_{60}{ }^{2}$. Later on it became clear that the vibrational spectra of all metal fullerides ${ }^{3}$ exhibit mode-specific shifts and intensity variations associated with electron donation to the fullerene molecules from the metal atoms intercalated into the interstitial sites of the lattice. The physical origin of the effects of the charge transfer on the phonon spectrum were clarified by $a b$-initio calculations ${ }^{4}$ for $\mathrm{K}_{6} \mathrm{C}_{60}$ : the excess electrons are accommodated in the lowest unoccupied $\left(\mathrm{t}_{1 \mathrm{u}}\right)$ orbitals of $\mathrm{C}_{60}$ which have antibonding character leading to a structural relaxation of the molecule. This structural relaxation is primarily responsible for the frequency shifts, more specifically for the softening of the tangential modes. The intensity variations on the IR spectrum are instead mainly brought upon by electron-phonon coupling which plays an important role in the vibrational excitation process. A first theoretical approach to the problem was the charge-phonon model ${ }^{6}$ which considered the coupling of the dipole-active $T_{1} u$ modes to the $t_{1} u^{-t} 1 g$ electronic transitions. This model has subsequently been suggested to be oversimplified since couplings to many different electronic excitations have to be considered to get a consistent picture. ${ }^{4}$ However, the detailed understanding of the electron-phonon 
coupling in the fullerides is hampered by the complicated interplay between structural, vibrational and electronic properties in these compounds.

In this paper we contribute to this subject by investigating the electron-phonon coupling signatures in the vibrational spectra of $\mathrm{C}_{60}$ deposited onto metal surfaces. There the fullerenes are chemisorbed but the degree of hybridization between $\mathrm{C}_{60}$ orbitals and the substrate electronic states and the amount of charge transfer varies greatly from substrate to substrate. However, adsorbing the fullerene molecule on well defined substrates enables one 10 control the physical properties of the overlayer with a precision unmatched in bulk materials. Mode-specific shifts and intensity variations similar to those in fullerides have been observed in high-resolution electron energy loss ${ }^{8,9,10}$ and infrared ${ }^{11}$ spectra of $\mathrm{C}_{60}$ monolayers on bare and alkali-covered metal surfaces. Our aim here was to take advantage of intrinsic high brightness, high stability, and proportionality to the stored electron beam of synchrotron IR spectroscopy to elucidate the physical origin of these changes by recording also the IR broadband absorption on which the specific vibrational bands are superimposed. Both the vibrational bands and the broadband absorption revealed a surprisingly rich scenario for the vibrational dynamics of $\mathrm{C}_{60}$ comprising both electron-phonon and purely vibrational coupling. During the adsorption on $\mathrm{Ag}(111), \mathrm{Au}(110)$ and $\mathrm{Cu}(100)$ we found a broadband reflectance decrease typical of what Persson and Volokitin ${ }^{12}$ were able to explain as a friction phenomenon between the adsorbate vibrations with a component of velocity oscillating parallel to the surface (such as the frustrated translations and rotations) and motion of the conduction electrons within the skin depth and driven by the external electric field bring about by the IR light (see also ref.13). At the same time a vibrational mode which is not IR-active for the isolated molecule appears and shows a temperature dependent frequency and bandwidth change characteristic of a change in adsorption state and an anharmonic coupling ${ }^{14}$ to a low frequency mode. This low frequency mode lies within the energy domain of the frustrated translation of the $\mathrm{C}_{60}$. When the metal surfaces were pre-dosed with potassium we found an antiabsorption lineshape for the new IR-active mode accompanied by an increase in broadband reflectance during $\mathrm{C}_{60}$ adsorption, indicating that now the coupling of the vibrational mode to induced surface state has become the process which dominates the IR spectrum.

\section{EXPERIMENTAL}

The IR spectra were collected with the synchrotron infrared reflection-absorption spectroscopy set-up of beamline U4IR at the National Synchrotron Light Source which is described in detail elsewhere ${ }^{15}$. The use of a synchrotron source is strictly necessary for these experiments since a thermal infrared source is subject to temperature fluctuations which cause uncertainty in the incident beam intensity. The synchrotron radiation brightness, on the other hand, is determined only by the stored current which can be accurately measured for the normalization of each of the spectra. This normalization procedure can be adopted only if another crucial requirement is fulfilled, i.e. the electron beam position in the ring remains stable during the whole experiment. At the National Synchrotron Light Source this stability is achieved by means of a global feedback system ${ }^{16}$ developed some years ago, which continues to be improved. The broadband IR-reflectance change and the absorption bands were measured during $\mathrm{C}_{60}$ deposition collecting a spectrum ( 256 co-added scans) at a resolution of 4 $\mathrm{cm}^{-1}$ over each $90 \mathrm{~s}$ of dosing. In order to avoid instabilities, which can result in intensity oscillations within the spectral distribution of the broadband reflectance change, we adopted a stringent procedure of data selection: 5 spectra of 256 scans each were recorded before starting the fullerene deposition; the last spectrum was ratioed to the first, and exposure to $\mathrm{C}_{60}$ was initiated only if a "flat" baseline was obtained between 180 and $500 \mathrm{~cm}^{-1}$ for the bolometer, or $300-3000 \mathrm{~cm}^{-1}$ for the $\mathrm{Cu}: G e$ detector. $\mathrm{C}_{60}$ was deposited onto the metal surfaces by resistive heating of a tantalum crucible to about $700 \mathrm{~K}$. The pressure in the chamber rose from $1 \times 10^{-10}$ Torr to $9 \times 10^{-10}$ Torr during dosing. In order to avoid an additional source of baseline drift in the spectra due to the thermal loading of the metallic substrate, a deposition rate of approximately 15 minutes per monolayer was used. The deposition time corresponding to the completion of one fullerene monolayer (ML) was calibrated by saturating the substrate kept at or slightly above $(570 \mathrm{~K})$ the desorption temperature of the multilayer (455 $\mathrm{K})^{17}$ and measuring the ratio of the overlayer/substrate Auger peaks. Auger spictra were also collected after each IR experiment to check the fullerene coverage. At the beginning of each experiment, the $\mathrm{Ag}(111), \mathrm{Au}(110)$ or $\mathrm{Cu}(100)$ single crystal was cleaned by cycles of $\mathrm{Ar}^{+}$sputtering followed by annealing to restore the surface ordering, until no impurities could be detected by Auger spectroscopy and sharp LEED patterns were observed. For alkali deposition during which the pressure in the chamber never exceeded $2 \times 10^{-10}$ Torr, a thoroughly outgassed $\mathrm{K}$ getter was used. For each exposure, the same data selection procedure was followed to make sure that no drift was present. The substrate temperature was monitored by a thermocouple inserted in a hole in the substrate and could be varied by filling the sample manipulator with liquid $\mathrm{N}_{2}$ and by resistive heating. 


\section{RESULTS AND DISCUSSION}

Figure 1 shows the IR spectra collected during deposition on a $\mathrm{Cu}(100)$ substrate held at room temperature. One clearly distinguishes only one IR band at $1440 \mathrm{~cm}^{-1}$ superimposed on a broadband IR reflectance change. The amplitudes of both features increase with fullerene coverage and saturate when a complete monolayer is reached. We note that with our slow deposition rate the growth at room temperature proceeds layer by layer as verified by measuring the ratio of the overlayer/substrate Auger peaks vs. deposition time (not shown). The overall reflectance shape remains unchanged.

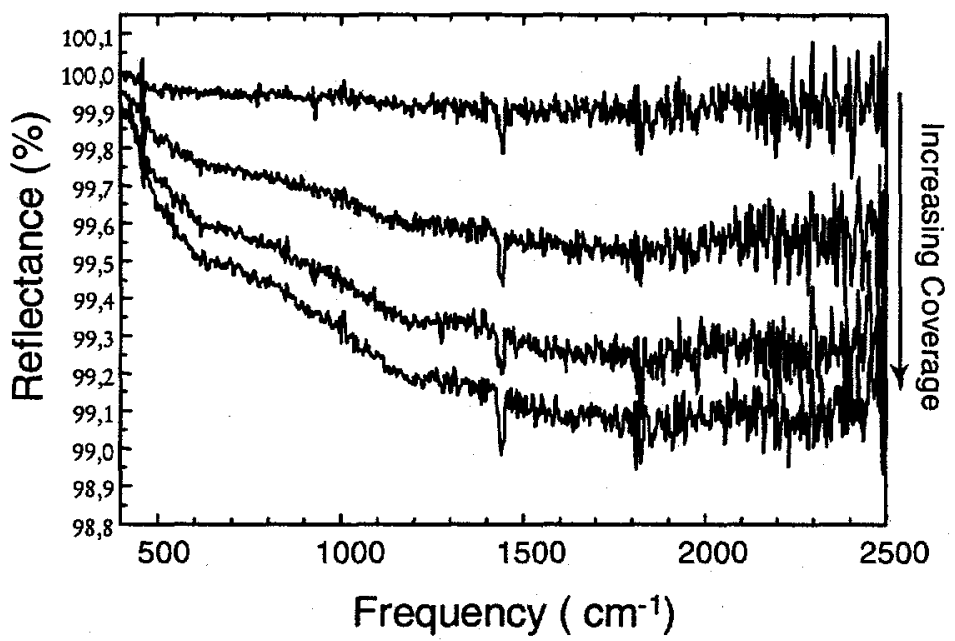

Figure 1: Infrared spectra in the $400-2500 \mathrm{~cm}^{-1}$ region of a $\mathrm{Cu}(100)$ surface collected during $\mathrm{C}_{60}$ deposition at room temperature. A broadband reflectance change as well as one absorption band at $1440 \mathrm{~cm}^{-1}$ are clearly seen.

Similar experiments were performed on $\mathrm{Ag}(111)$ and $\mathrm{Au}(110)$ and the broadband reflectance change associated with the deposition of one monolayer of $\mathrm{C}_{60}$ on each of the three single crystal substrates is shown in figure 2. The specific vibrational bands also visible in the spectra will be discussed later. Here we note that the broadband IR reflectivity change has a frequency dependence in good agreement with the theory which considers the electronic energy dissipation arising from the scattering of the substrate conduction electrons by the adsorbate. ${ }^{12,18}$ The relative motion between the sliding adsorbate and the electron "fluid" will give rise to a drag-force action on the adsorbate. So one can define an electronic friction coefficient which has been set to be equal to the inverse lifetime of the frustrated translation of the adsorbate due to creation of electron-hole pairs. The microscopic theory of the friction ${ }^{19}$ based on the Newns-Anderson model of chemisorption, expresses this electronic friction coefficient in terms of the width of the adsorbate-induced resonance state, $\Gamma$, the adsorbate-induced density of states at the Fermi level, $\rho\left(E_{F}\right)$, and a term which accounts for the electron transfer interaction between the adsorbate orbital and metal states. According to the diffuse scattering model, the friction coefficient can be obtained from the asymptotic "high frequency "value of the IR reflectance change

$$
\Delta R_{p}=-\frac{4}{c} \frac{n_{a}}{n} \frac{M}{m} \frac{\eta}{\cos \Theta} F
$$

where $F$ is a correction factor which is important at grazing incidence geometry ${ }^{20}, \mathrm{~F}=\cos ^{2} \theta /\left(\cos ^{2} \theta+\omega^{2} / \omega_{\mathrm{p}}{ }^{2}\right)$, and $\theta, \mathrm{rn}, \omega_{\mathrm{p}}, \omega$ and $n_{a}$ are the angle of incidence, the electron mass, the plasma frequency, the frequency of the light and the density of the adsorbate respectively. The broken lines in figure 2 are the fits of the experimental data to this theory, which were obtained using the plasma frequencies of 74560,65760 and $87100 \mathrm{~cm}^{-1}$, and the skin depths of $31.5,35.8$ and $27 \mathrm{~nm} \mathrm{for} \mathrm{Ag,} \mathrm{Au} \mathrm{and}$ $\mathrm{Cu}$, respectively. The asymptotic limits of the reflectance change are $1 \pm 0.1 \%$ for $\mathrm{Ag}(111)$ and $\mathrm{Au}(110)$ and $0.8 \pm 0.1 \%$ for $\mathrm{Cu}(100)$. Accounting for the $\mathrm{C}_{60}$ mass $\left(720 \times 1.66 \times 10^{-27} \mathrm{~kg}\right)$ and the average density for one monolayer of $\mathrm{C}_{60}$ on noble metal surfaces $\left(\approx 1.15 \times 10^{-2} \AA^{-2}\right)$, the friction coefficient is found to be $2.08 \times 10^{9} \mathrm{~s}^{-1}$ for $\mathrm{C}_{60}$ on $\mathrm{Ag}(111)$ and $\mathrm{Au}(11.0)$, and $1.66 \times 10^{9} \mathrm{~s}^{-1}$ for $\mathrm{C} 60$ on $\mathrm{Cu}(100)$.

The same scattering mechanism of the substrate conduction electrons by the adsorbate will also cause a resistance change in a metallic thin film when adsorbates are chemisorbed on the surface. ${ }^{12,15,18}$ Our results can therefore be compared with resistance change measurements during $\mathrm{C}_{60}$ deposition on copper films evaporated on sapphire substrates, where a value of $5 \AA^{2}$ for the scattering cross section of the adsorbed molecules has been found. ${ }^{21}$ Using the bulk parameters of copper, a friction coefficient of $9.4 \times 10^{8} \mathrm{~s}^{-1}$ can be deduced, which is in fairly good agreement with the value obtained from IR 
reflectance measurements, considering the differences in surface structure. Thus we can deduce that the diffuse scattering model $^{12,15,18}$ also accounts for the shape and amplitude of the broadband IR reflectance change induced by the adsorption of large molecules like $\mathrm{C}_{60}$.
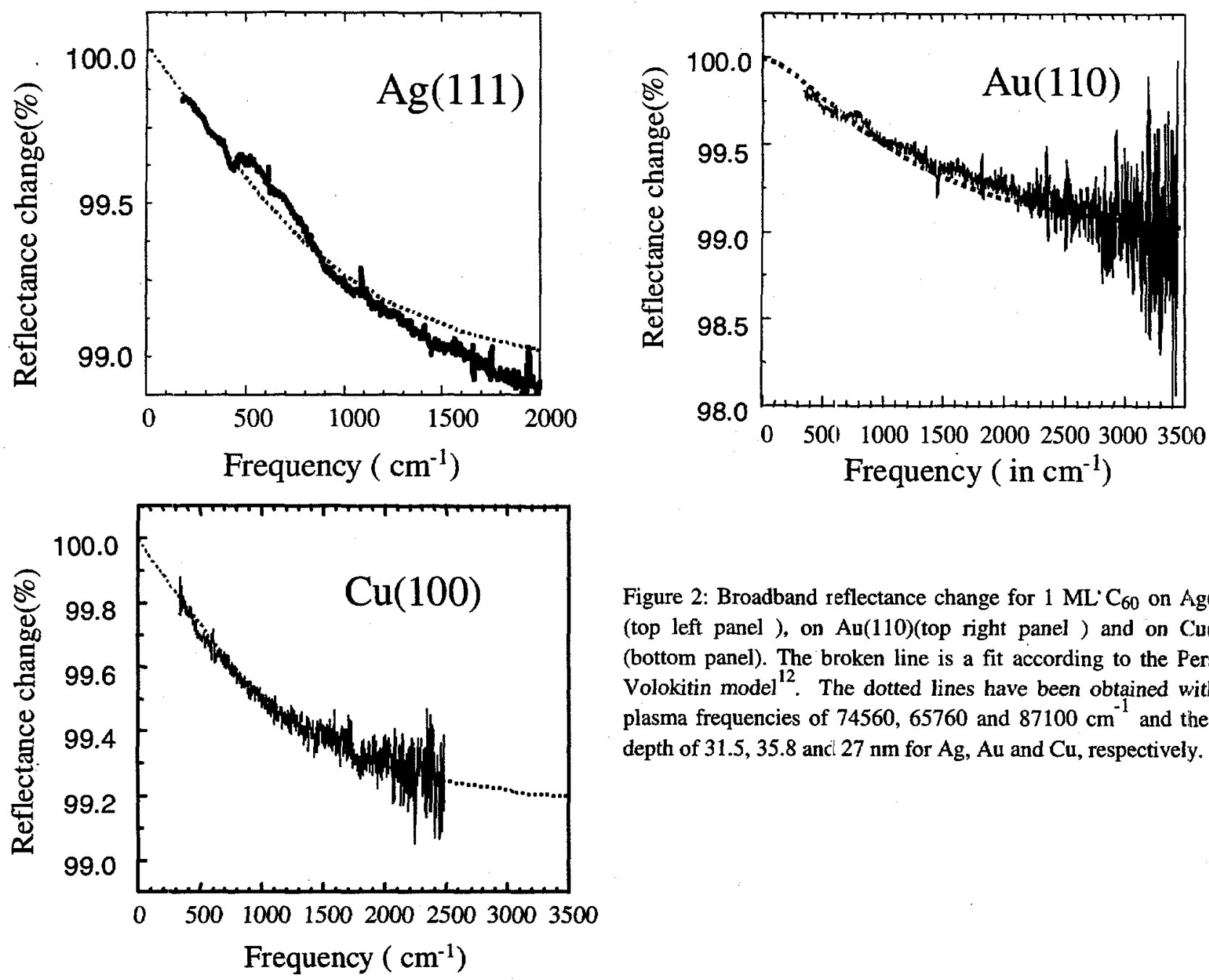

Figure 2: Broadband reflectance change for $1 \mathrm{ML} \cdot \mathrm{C}_{60}$ on $\mathrm{Ag}(111)$ (top left panel ), on $\mathrm{Au}(110)$ (top right panel ) and on $\mathrm{Cu}(100)$ (bottom panel). The broken line is a fit according to the PerssonVolokitin model ${ }^{12}$. The dotted lines have been obtained with the plasma frequencies of 74560,65760 and $87100 \mathrm{~cm}^{-1}$ and the skin depth of 31.5, 35.8 ancl $27 \mathrm{~nm}$ for $\mathrm{Ag}$, $\mathrm{Au}$ and $\mathrm{Cu}$, respectively.

The friction coefficients obtained for all three metal surfaces is proportional to the inverse lifetimes of the frustrated translation of the adsorbate due to creation of electron-hole pairs of the order of hundreds of picoseconds and this can be considered an independent confirmation of the metallic character of the $\mathrm{C} 60$ monolayer, previously deduced from direct $^{22,23}$ and inverse ${ }^{24,25}$ photoemission data. The values of the friction coefficient are about 6 times smaller than that found for $\mathrm{CO}$ adsorbed on $\mathrm{Cu}(111)$ films. ${ }^{15}$ Thus, the product $\Gamma \rho\left(\mathrm{E}_{\mathrm{F}}\right)$ is about 4 times higher for $\mathrm{C}_{60}$ adsorbed on noble metal surfaces, compared to $\mathrm{CO}$. For the $\mathrm{CO} / \mathrm{Cu}$ (111) system, the $2 \pi^{*}$ state is known to lie at $\sim 3.35 \mathrm{eV}$ above the Fermi level, with a width of $0.1 \mathrm{eV}<\Gamma<0.6 \mathrm{eV} .^{26,27}$ For $C_{60}$ on the three metallic substrates, the width of the LUMO ( $\pi^{*}$ character) is difficult to evaluate: direct ${ }^{23}$ and inverse ${ }^{24,25}$ photoemission data show rather broad spectral features both for the occupied and the unoccupied parts of the LUMO. However, by comparison vith the HOMO band, it seems plausible that most of this width is due to vibronic coupling and that the actual bandwidih amounts to less than $0.1 \mathrm{eV}^{28}$ One therefore deduces that the adsorbate-induced $\rho\left(E_{F}\right)$ is much larger for $C_{60}$ than for $C_{C O}$.

Let us turn our attention now to the specific vibrational bands of the molecule: figure 3 shows the spectral region between 1250 and $1600 \mathrm{~cm}^{-1}$ of the IR spectra acquired while dosing $\mathrm{C}_{60}$ onto $\mathrm{Ag}(111)$ at room temperature. As the coverage increases, a band at $1442 \mathrm{~cm}^{-1}$ appears and shifts to higher wavenumbers. Only very close to monolayer coverage (last spectrum) a second band centered at $1388 \mathrm{~cm}^{-1}$ can be discerned. No additional bands are seen at lower wavenumbers. The spectra for room temperature adsorption on the other two metals are similar: a detailed inspection of the spectrum in Fig. 2 
for $1 \mathrm{ML} \mathrm{C} 60$ on $\mathrm{Cu}(100)$ shows only a weak band at $1357 \mathrm{~cm}^{-1}$ and a stronger one at $1440 \mathrm{~cm}^{-1}$ while for $1 \mathrm{ML} \mathrm{C}_{60}$ on $\mathrm{Au}(110)$ only one strong band at $1445 \mathrm{~cm}^{-1}$ can be seen. In order to better understand these features we performed another experiment in which the fullerene molecules were prevented from chemisorption onto the $\mathrm{Cu}(001)$ substrate by a precoverage of $1 \mathrm{ML}$ of $\mathrm{CO}$. The IR spectrum is shown in figure 4 corresponds to a nominal coverage of $1 \mathrm{ML}$ of $\mathrm{C}_{50}$. The very strong band at $2083 \mathrm{~cm}^{-1}$ is the $\mathrm{CO}$ stretching. One can also very clearly see the first three $\mathrm{T}_{1 \mathrm{u}}$ modes at practi-
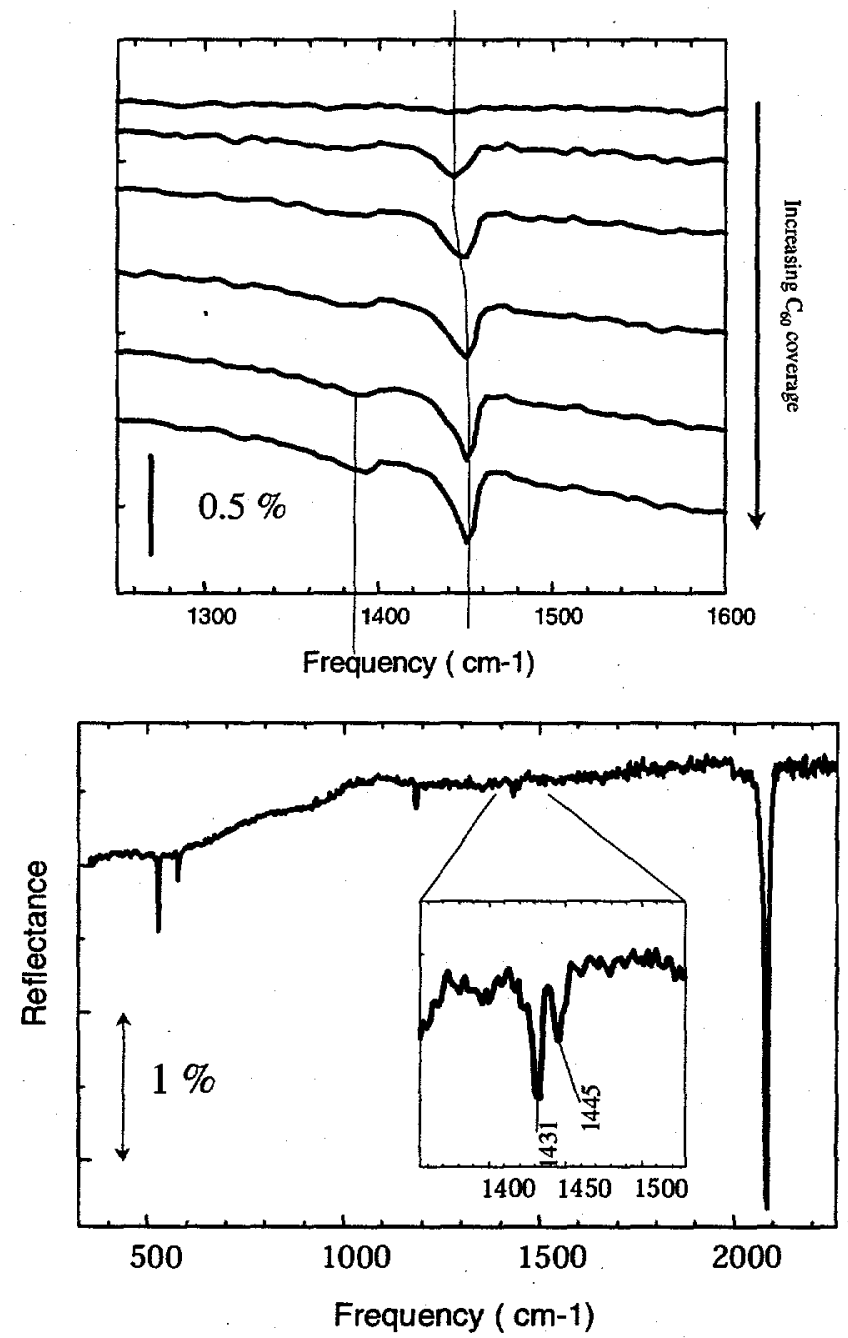

Figure 3: Infrared spectra in the $1250-1600 \mathrm{~cm}^{-1}$ region of a $\mathrm{Ag}(111)$ surface collected during $\mathrm{C}_{60}$ deposition at room temperature.
Figure 4: Infrared spectra in the $400-2250 \mathrm{~cm}^{-1}$ region of a $\mathrm{Cu}(100)$ surface precovered with $1 \mathrm{ML} \mathrm{CO}$ collected during $\mathrm{C}_{60}$ deposition at $90 \mathrm{~K}$.

cally the same frequency as for bulk $\mathrm{C}_{60}$. However, in the spectral region of the $\mathrm{T}_{1 \mathrm{u}}(4)$ of bulk $\mathrm{C}_{60}$ two bands are seen at $1431 \mathrm{~cm}^{-1}$ and $1445 \mathrm{~cm}^{-1}$, respectively but it is the former which is more intense. The breaking of symmetry due to the presence of the surface induces, therefore the appearance of a new infrared active mode, as already seen previously for $\mathrm{C}_{60}$ adsorption on $\mathrm{H}$-terminated $\mathrm{Si}(111)^{29}$ and at the surface of $\mathrm{C}_{60}$ and fulleride crystals ${ }^{30,31}$. This new mode has been attributed $^{30,31}$ to the $\mathrm{Ag}$ (2) Raman mode, and this attribution has been adopted also in a combined IR and SFG study ${ }^{11}$ of $\mathrm{C}_{60} / \mathrm{Ag}$. From the comparison of figures 1 and 4 one deduces that the visibility of all $\mathrm{C}_{60}$-induced IR bands does not depend on instrumental sensitivity, and that in the case of chemisorbed fullerenes on metals the intensity of the $\mathrm{T}_{1 \mathrm{u}}$ modes is depressed while that of the $\mathrm{Ag}_{\mathrm{g}}(2)$ is enhanced due to electron-phonon coupling effects similar to those observed in fullerides. ${ }^{2,31}$ We note that the intensity enhancement of the $\mathrm{Ag}_{\mathrm{g}}(2)$ mode for $\mathrm{C}_{6} \mathrm{O} / \mathrm{Ag}$ has been attributed to the dynamical charge transfer between the metallic substrate and the $\mathrm{C}_{60}$ molecule $^{32}$ but we believe, as shall be clear in the following, that this mechanism does not explain the phenomenon.

We have also studied the temperature dependence of the IR spectra as shown in figure 5. The top left panel shows the evolution of the spectral region between 1200 and $1650 \mathrm{~cm}^{-1}$ when a $\mathrm{C}_{60}$ monolayer deposited on $\mathrm{Cu}(100)$ at $90 \mathrm{~K}$ is heated stepwise to $375 \mathrm{~K}$. While the $\mathrm{T}_{1 \mathrm{u}}(4)$ mode stays at constant frequency but decreases in intensity, the $\mathrm{Ag}(2)$ mode is seen to 
shift from $1451 \mathrm{~cm}^{-1}$ to $1440 \mathrm{~cm}^{-1}$ and to broaden considerably. The detailed freouency behavior of the $A_{g}(2)$ mode is plotted in the top right panel of figure 5: if one performs repeated heating-cooling cycles between $90 \mathrm{~K}$ and $600 \mathrm{~K}$ the $\mathrm{Ag}_{\mathrm{g}}(2)$ mode does not shift back to the initial frequency after the first heating. This indicates that an irreversible phase tran-
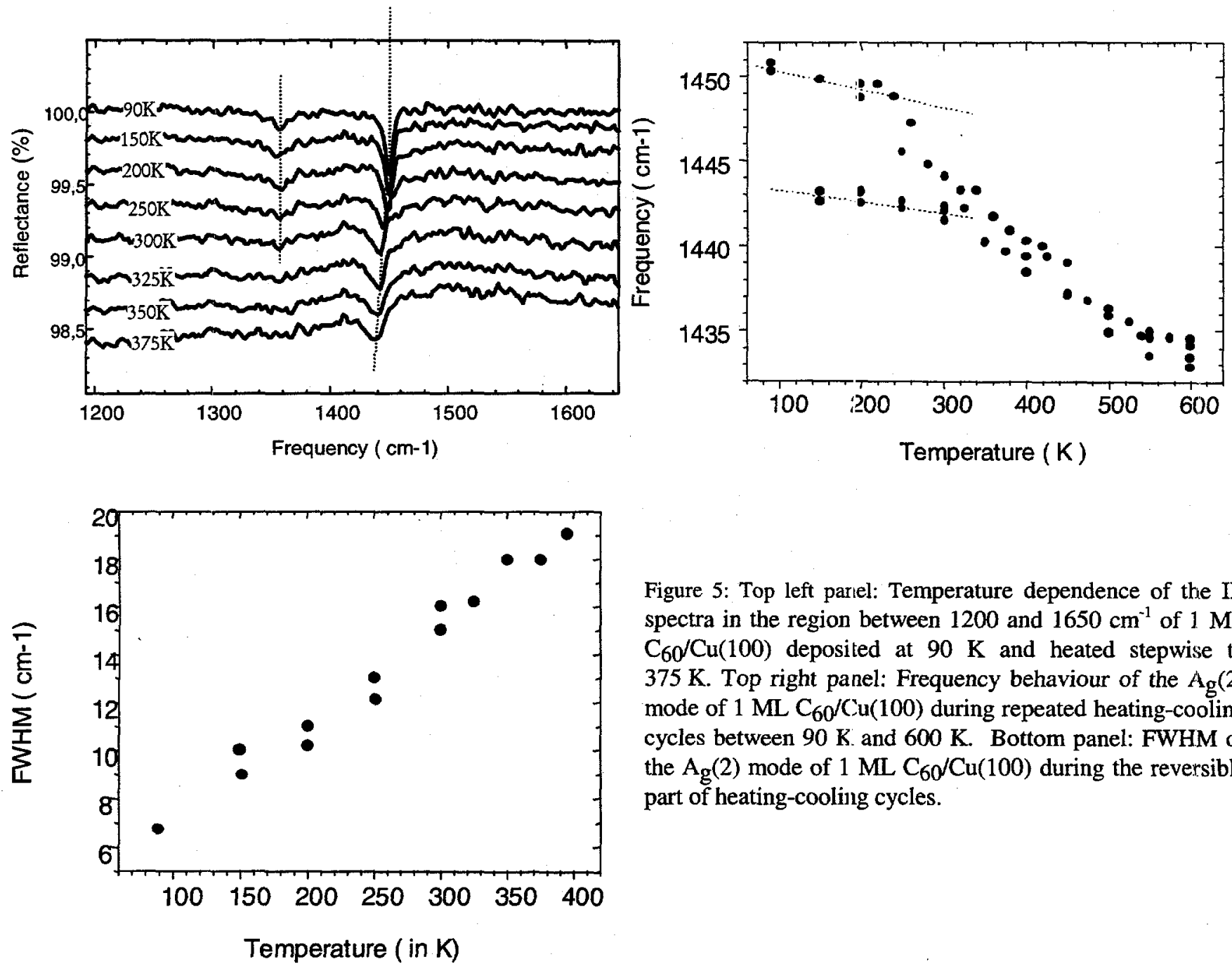

Figure 5: Top left pariel: Temperature dependence of the IR spectra in the region between 1200 and $1650 \mathrm{~cm}^{-1}$ of $1 \mathrm{ML}$ $\mathrm{C}_{60} / \mathrm{Cu}(100)$ deposited at $90 \mathrm{~K}$ and heated stepwise to $375 \mathrm{~K}$. Top right panel: Frequency behaviour of the $\mathrm{Ag}(2)$ mode of $1 \mathrm{ML} \mathrm{C}_{60} / \mathrm{Cu}(100)$ during repeated heating-cooling cycles between $90 \mathrm{~K}$. and $600 \mathrm{~K}$. Bottom panel: FWHM of the $\mathrm{Ag}_{\mathrm{g}}(2)$ mode of $1 \mathrm{ML} \mathrm{C}_{60} / \mathrm{Cu}(100)$ during the reversible part of heating-cooling cycles.

sition to a different adsorption state has occurred. Similar phase transitions have been observed on other metal surfaces and are a signature of the existence of activation barriers between metastable and stable adsorption geometries, sometimes accompanied by reconstruction of the substrate. ${ }^{33}$ However, the reversible part of the frequency shift and the broadening of the $A_{g}(2)$ band are typical of an anharmonic coupling to a low frequency vibrational mode, also called dephasing, which becomes more and more important as the coupled mode becomes populated with increasing temperature. The theory for this mechanism is a phase relaxation exchange model ${ }^{14}$ and allows to extract the frequency, $\omega_{0} \approx 45-75 \mathrm{~cm}^{-1}$, of the coupled mode from the plot shown in the bottom panel of figure 5 which shows the temperature dependence of the FWHM of the $\mathrm{Ag}_{\mathrm{g}}(2)$ band. Given that this value of $\omega_{b}$ is too low to be attributed to an internal mode of the fullerene, we suggest that it might be the frustrated translation of the $\mathrm{C}_{60}$ on the metal surface which couples to the $\mathrm{Ag}_{\mathrm{g}}(2)$ mode.

In order to gain further insight dependence of the IR spectra on charge transfer we have also studied the doping of the chemisorbed $\mathrm{C}_{60}$ molecules through co-adsorbed potassium as illustrated in figure 6 . When $\mathrm{K}$-dosing has been performed on top of a room-temperature deposited $1 \mathrm{ML} \mathrm{C} 60 / \mathrm{Cu}(100)$ as shown in Fig. 6 top panel, the $\mathrm{Ag}_{\mathrm{g}}(2)$ band is seen to shift to lower frequency while its linewidth decreases. At $\mathrm{K}$ coverages very close to saturation decreases drastically in intensity while still redshifting while the $\mathrm{T}_{1 \mathrm{u}}(4)$ mode suddenly increases in intensity. This behaviour is very similar to what has been observed in analogous experiments ${ }^{11}$ where $\mathrm{K}$ was dosed on $1 \mathrm{ML} \mathrm{C}_{6} / \mathrm{Ag}(111)$. Given that highest charge transfer 
obtainable by this doping procedure on $\mathrm{Au}$ and $\mathrm{Ag}$ surfaces ${ }^{8,10,11}$ has been found to be 6 electrons per fullerene we assume that the same is true on $\mathrm{Cu}(100)$. This leads us to conclude that the $\mathrm{Ag}_{\mathrm{g}}(2)$ shifts linearly by about $5 \mathrm{~cm}^{-1}$ per transferred electron, while the $T_{1 u}(4)$ mode shifts in a strongly non linear fashion as already observed by HREELS ${ }^{10}$ for $\mathrm{C}_{60}+\mathrm{Cs} / \mathrm{Au}(110)$. Based on the linear shift of the $\mathrm{Ag}_{\mathrm{g}}(2)$ mode the charge transfer per fullerene molecule in $1 \mathrm{ML} \mathrm{C}_{60}$ on $\mathrm{Au}(110)$ and $\mathrm{Ag}(111)$ (see fig. 2 and 3) can be estimated to be about 1 electron while it amounts to about 2 electrons/fullerene in $1 \mathrm{ML} \mathrm{C}_{60}$ on $\mathrm{Cu}(100)$. These values are in very good agreement with previous estimates based on HREELS $^{9}$ and photoemission ${ }^{23}$ data, however they have to be considered with caution since the anharmonic coupling of the $\mathrm{Ag}_{\mathrm{g}}(2)$ mode to the frustrated translational mode might influence the shift differently on the different surfaces.

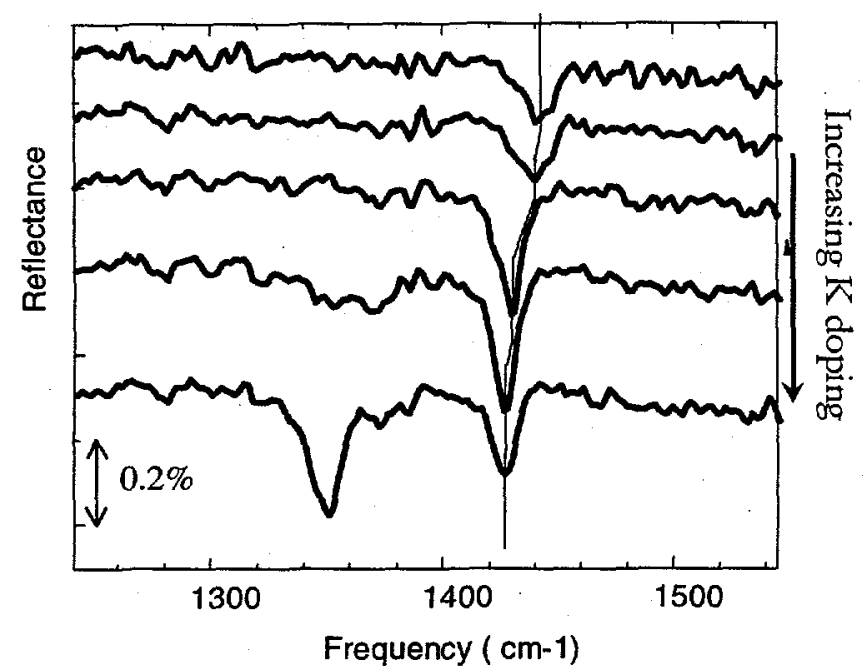

Figure 6: Top panel: Infrared spectra in the $1225-1550 \mathrm{~cm}^{-1}$ region collected during $\mathrm{K}$ dosing on top of $1 \mathrm{ML} \mathrm{C}_{60} / \mathrm{Cu}(100)$ deposited at room temperature. Bottom left panel: Infrared spectra in the $1300-1600 \mathrm{~cm}^{-1}$ region collected during room temperature $\mathrm{C}_{60}$ dosing on top of $1 \mathrm{ML} \mathrm{K} / \mathrm{Ag}(111)$. Bottom right panel: Infrared spectra in the $1325-1550 \mathrm{~cm}^{-1}$ region collected during room temperature $\mathrm{C}_{60}$ dosing on top of $1 \mathrm{ML} \mathrm{K/Au}(110)$.
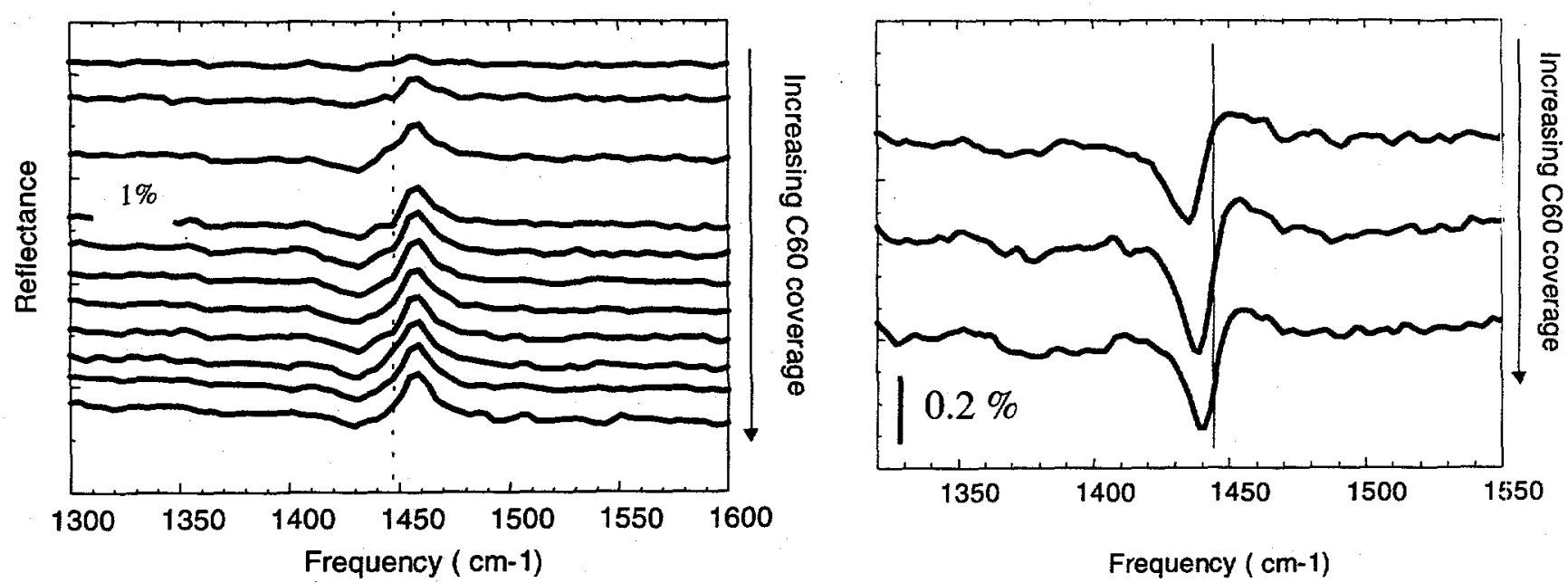

Let us now consider the potassium doping of $\mathrm{C}_{60}$ on $\mathrm{Ag}(111)$ and $\mathrm{Au}(110)$ which is illustrated in the bottom panels of fig.6 were we plot the evolution of the IR spectra during fullerene deposition onto the metal surfaces pre-covered by $1 \mathrm{ML}$ of $\mathrm{K}$. For the adsorption on gold (bottom right panel) we notice that similarly to $\mathrm{K}$ dosing on top of $1 \mathrm{ML} \mathrm{C}_{60} / \mathrm{Cu}(100)$ discussed above, the $\mathrm{Ag}_{\mathrm{g}}(2)$ band redshifts compared to the undoped monolayer. This agrees well with previous studies which find that the charge transfer for $1 \mathrm{ML} \mathrm{C}_{60} / 1 \mathrm{ML} \mathrm{K} / \mathrm{Au}(110)$ is -3 electrons per fullerene ${ }^{34}$. However, a new characteristic of this system is that the shape of the $\mathrm{Ag}_{\mathrm{g}}(2)$ band now derivative like as for an antiabsorption line. For adsorption on $\mathrm{K}$-predosed $\mathrm{Ag}$ (111) shown in the bottom right panel the antiabsorption line character becomes even the dominant feature in the spectrum. These features point again to strong electron-phonon coupling and ressemble those observed previously for hydrogen adsorption on transition metals ${ }^{35}$ issuing from the coupling of the adsorbate vibration to an adsorbate-induced electronic surface state. This coupling mechanism is characterized by an increase in broadband reflectance. ${ }^{35}$ We therefore took again advantage of the possibilities of the Synchrotron radiation IR set-up to measure the broadband reflectance change 
during $\mathrm{K}$ dosing onto the $\mathrm{C}_{60}$ monolayers deposited on the three metal substrates. The results are shown in figure 7 . We note that these measurements are extremely demanding since one has to avoid thermal loading of the metallic substrate by the $\mathrm{K}$ getter source which is kept at $\sim 900 \mathrm{~K}$. The evolution of the broadband reflectance clearly shows an increase with potassium dosing confirming the coupling of the $\mathrm{Ag}_{\mathrm{g}}(2)$ mode to an electronic surface state.
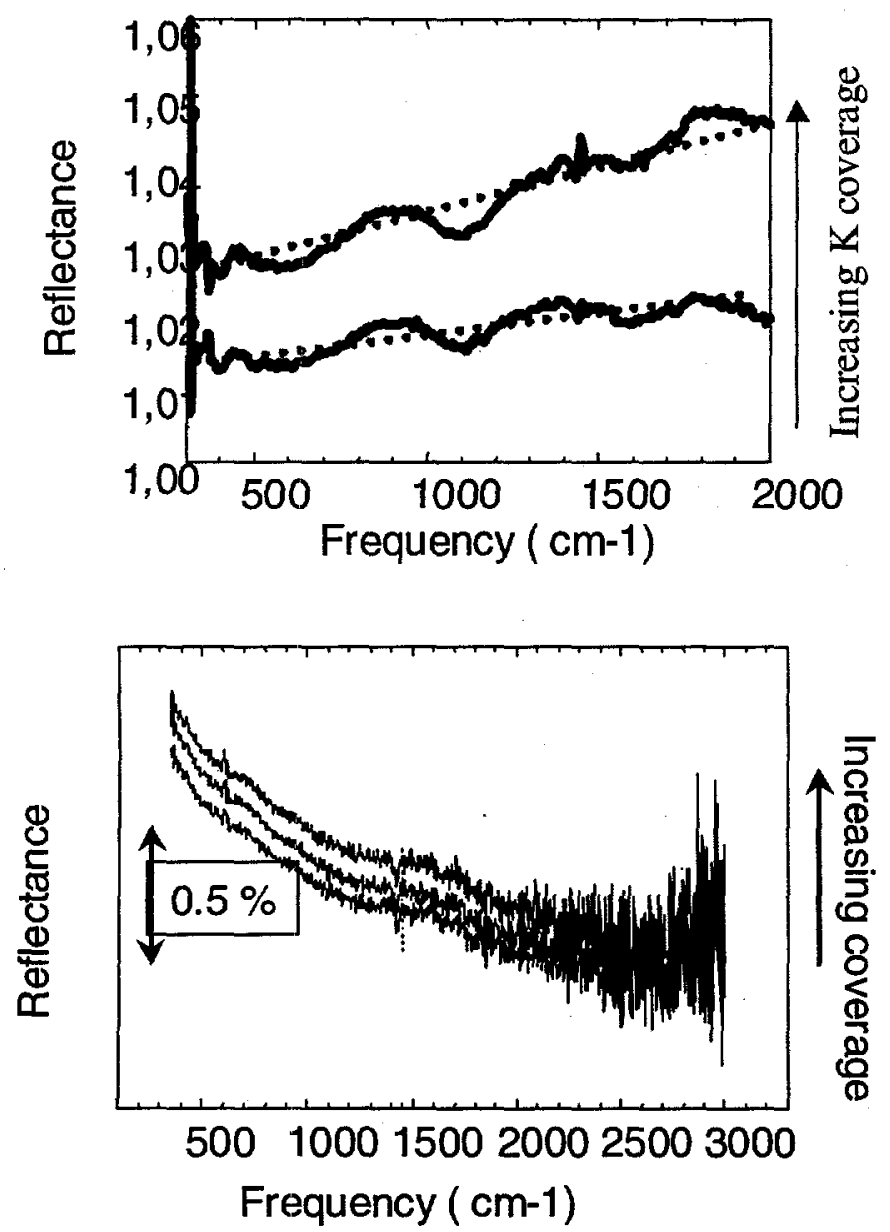

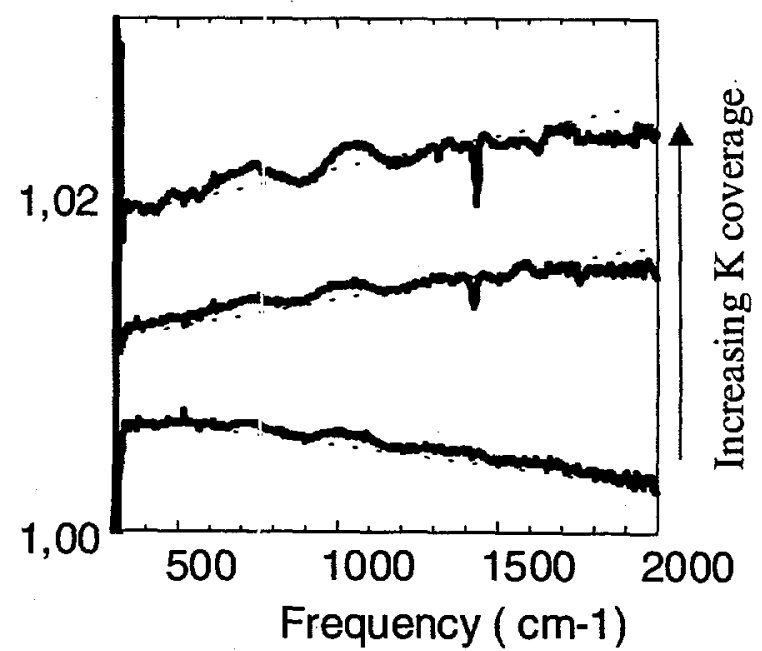

Figure 7: Broadband reflectance change recorded during $\mathrm{K}$ dosing onto $1 \mathrm{ML} \mathrm{C}_{60}$ on $\mathrm{Ag}(111)$ (top left panel ), on $\mathrm{Au}(110)$ (top right panel ) and on $\mathrm{Cu}(100$; (bottom panel).

\section{SUMMARY}

Synchrotron Infrared Studies of chemisorbed $\mathrm{C}_{60}$ on bare and potassium-precovered $\mathrm{Ag}(111), \mathrm{Au}(110)$ and $\mathrm{Cu}(100)$ have revealed several new insights into electron-phonon and purely vibrational couplings in these systems. In the case of adsorption on the clean metal substrates the overall behavior of the IR reflectance cinange is dominated the diffuse scattering mechanism of the conduction electrons of the metallic substrate by the adsorbate. This broadband reflectance change allows to determine the friction coefficient between the sliding adsorbate and the free conduction electrons of the metal driven by the external electric field associated with the incident IR photons. The values obtained for the friction coefficient give an independent confirmation of the metallic character of the fullerene-substrate bond and of the high density of adsorbate induced states close to the Fermi level. Superimposed on the broadband reflectance are the individual vibrational bands of the adsorbate: a non-IR active mode becomes active upon adsorption and that its frequency shifts proportionally to the charge transferred from the metal to the molecule by about $5 \mathrm{~cm}^{-1}$ per electron. The temperature dependence of the frequency and the width of this IR feature, attributed to the normally Raman active $A_{g}(2)$ mode, has also been followed for $\mathrm{C}_{60} / \mathrm{Cu}(100)$ and was found to agree.well with a weak anharmonic coupling (dephasing) between this newly active mode and the frustrated translational mode of the adsorbed molecules. When potassium is co-adsorbed with $\mathrm{C}_{60}$ allowing for a 
larger charge transfer to the fullerene, a new electron-phonon coupling mechanism becomes dominant in determining the shape of the IR spectra, namely the coupling of the $A_{g}(2)$ mode to induced surface states. This coupling manifests itself through a broadband reflectance increase and a derivative-like shape of the $\mathrm{A}_{\mathrm{g}}(2)$ band. In addition, the comparison with co-adsorption experiments of $\mathrm{CO}$ and $\mathrm{C}_{60}$ allowed to identify intensity variations of the $\mathrm{T}_{1 \mathrm{u}}$ infrared bands which occur both with and without co-adsorption of $\mathrm{K}$ similar to those observed in alkali fullerides. Given the hybridization between $\mathrm{C}_{60}$ and metal substrate electronic states, these intensity variations are probably caused by the coupling to induced surface states.

\section{ACKNOWLEDGEMENTS}

We would like to thank B. N. J. Persson for numerous important discussions. Research at Brookhaven National Laboratory was performed under the auspices of the US Department of Energy, contract $\mathrm{N}^{\circ}$ DE-AC02-76CH00016 and the Belgian National Fund for Scientific Research (FNRS). This project has also received financial support from the European Community of the European Community HCM contract ERB CHRX-CT940580 and TMR contract ERB FMRX-CT970155.

\section{REFERENCES}

1. For reviews see for ex. J. H. Weaver and D. M. Poirier, "Solid State Properties of Fullerenes and Fullerene-based Materials", in Solid State Physics, Ed.s H. Ehrenreich and F. Spaepen (Academic Press, New York, 1994), Vol. 48, pp.1-62;. Warren E. Pickett, "Electrons and Phonons in C60-based Materials", ibid., pp. 225-347.

2. K. J. Fu, W.L.Karney, O. L. Chapman, S. M. Huang, R. B. Kaner, F. Dietrich, K. Holczer, R. L. Whetten, "Giant vibrational resonances in A6C60 compounds", Phys. Rev.B vol. 46, pp. 1937-1940, 1992.

3. See for example: H. Kuzmany, R. Winkler and T. Pichler, "Infrared spectroscopy of fullerenes", J. Phys.: Condens. Matter vol. 7, pp. 6601-6624, 1995.

4. P. Giannozzi and W. Andreoni, "Effects of doping on the vibrational properties of $\mathrm{C}_{60}$ from first principles: $\mathrm{K}_{6} \mathrm{C}_{60}$ ", Phys. Rev. Lett. vol.7, pp. 4915-4918, 1996.

5. W. Andreoni, P. Giannozzi and M. Parinello,"Molecular structure and chemical bonding in $\mathrm{K}_{3} \mathrm{C}_{60}$ and $\mathrm{K}_{6} \mathrm{C}_{60}$ ", Phys. Rev. B vol. 51 pp. 2087-2097, 1995.

6. M. J. Rice and H. Y. Choi, "Charged-phonon absorption in doped C60", Phys. Rev. B vol.45, pp. 10173-10175, 1992.

7. For a review see for ex. P. Rudolf, " $\mathrm{C}_{60}$ Adsorption on Metal Surfaces", in Fullerenes and Fillerene Nanostructures, ed.s H. Kuzmany, J. Fink, M. Mehring, and S. Roth, World Scientific, Singapore, pp.263-275, 1996.

8. S. Modesti, S. Cerasari, and P. Rudolf, "Determination of charge states of $\mathrm{C}_{60}$ adsorbed on metal surfaces", Phys. Rev. Lett. vol.71, pp. 2469-2473, 1993.

9. M. R. C. Hunt, S. Modesti, P. Rudolf and R. E. Palmer, "Charge Transfer and Structure in $\mathrm{C}_{60}$ Adsorption on Metal Surfaces", Phys. Rev. B vol. 51, pp. 10039-10047, 1995.

10. Michael R. C. Hunt, Petra Rudolf, Silvio Modesti, "A Photoemission and Electron Energy Loss Study of $\mathrm{C}_{60}$ monolayers adsorbed on $\mathrm{Cs}$ precovered $\mathrm{Au}(110)$, and of bulk, distilled $\mathrm{Cs}_{\mathrm{X}} \mathrm{C}_{60}$ ", Phys. Rev. B vol.55 pp. 7889 $7903,1997$.

11. Y. Caudano, A. Peremans, P. A. Thiry, P. Dumas, A. Tadjeddine, "Vibrational investigation of chemisorbed $\mathrm{C}_{60}$ by infrared-visible sum frequency generation spectroscopy", Surf. Sci. vol.377-379, pp. 1071-1075, 1997.

12. B. N. J. Persson and A. I. Volokitin, "On the origin of anti-absorption resonances in adsorbate vibrational spectroscopy”, Chem. Phys. Lett., vol. 185, pp. 292-296, 1991.

13. M. Hein, A. Otto, P. Dumas and G. P. Williams,' "Diffuse scattering of the conduction electrons of a metallic substrate by an adsorbate: an experimental study using synchrotron infrared radiation", these Proceedingsi, paper n.3775-24.

14. W. Erley and B.N.J. Persson, Surf. Sci. vol. 218, pp. 494, 1989.

15. M. Hein, P. Dumas, A. Otto, and G. P. Williams, "Friction of conduction electrons with adsorbates - Simultaneous changes of DC resistance and broadband IR reflectance of thin Cu(111) films exposed to CO", Surf. Sci., vol. 419, pp. 308-320, 1999.

16. L. H. Yu, E. Bozoki, J. Galayda, S. Krinsdy, and G. Vignola, "Real time harmonic closed orbit corrections", Nucl. Instrum. Methods A, vol. 268, pp. 284-288, 1989. 
17. L. H. Tjeng, R. Hesper, A. C. L. Heessels, A. Heeres, H. T. Jonkman, G. A. Sawatzky, "Development of the electronic structure in a K-doped $\mathrm{C}_{60}$ monolayer on a $\mathrm{Ag}(111)$ surface", Solid State Comm. vol.103, pp.31-35, 1997.

18. B. N. J. Persson, A. I. Volokitin, "Infrared reflection-absorption spectroscopy of dipole-forbidden adsorbate vibrations", Surf. Sci. vol. 310, pp. 314-336, 1994.

19. B. N. J. Persson, "Surface resistivity and vibrational damping in adsorbed layers", Phys. Rev. B, vol. 44, pp. 32773286, 1991.

20. A. Otto, M. Hein, to be published.

21. A. F. Hebard, R. R. Ruel, C. B. Eom, "Charge transfer and surface scattering at Cu-C60 planar interfaces", Phys. Rev. $B$ vol.54, pp. 14052-14060, 1996.

22. A. J. Maxwell, P. A. Brühwiler, A. Nilsson, N. Mårtensson and P. Rudolf, "Photoemission, autoionization and Xray absorption spectroscopy of ultrathin film C60 on Au(110)", Phys. Rev. E' vol.49, pp. 10717-10723, 1994.

23. B. W. Hoogenboom, R. Hesper, L. H. Tjeng, G. A. Sawatzky, "Charge transfer and doping dependent hybridization of C60 on noble metals", Phys. Rev. $B$ vol.57, pp. 11939-11942, 1998.

24. K. D. Tsuei, P. D. Johnson, "Charge transfer and a new image state of $\mathrm{C}_{60}$ ) on $\mathrm{Cu}(111)$ surface studied by inverse photoemission", Solid State Comm. vol.101, pp. 337-341, 1997.

25. M. Pedio, M. L. Grilli, C. Ottaviani, M. Capozi, C. Quaresima, P. Perfetti, P. A. Thiry, R. Caudano, P. Rudolf, "Inverse Photoemission Studies of $\mathrm{C}_{60}$ on $\mathrm{Au}(110)$ ", J. Electr. Spectr. Rel. Phen. vol. 76, pp. 405-409, 1995.

26. P. Avouris, R. E. Walkup, Annu. Rev. Phys. Chem. vol.40, pp.173, 1989.

27. C.J. Hirschmugl, G.P. Williams, B.N.J. Persson, A.I. Volokitin, "Adsorbate vibrational dynamics in the anomalous skin effect frequency region”, Surf. Sci. vol.317, pp. 1147, 1994.

28. P. A. Brühwiler, A.J. Maxwell, P. Baltzer, S. Andersson, D. Arvanitis, JL. Karlsson, N. Mårtensson, "Vibronic coupling in the photoemission bands of condensed C60", Chem. Phys. Lett. vol. 279, pp.85-91, 1997.

29. P. Dumas, M. Gruyters, P. Rudolf, Y. He, L.-M. Yu, G. Gensterblum, R. Caudano and Y. J. Chabal, "Vibrational Study of $\mathrm{C}_{60}$ overlayers on $\mathrm{H} / \mathrm{Si}(111)-(1 \times 1) "$, Surf. Sci. vol. 368, pp. 330-336, 1996.

30 André Rassat, Claude Fabre, Ali Messaoudi, Ralph Setton, René Ceolin, Patrick Bernier and Ahmed Zahab, "Surface effects and forbidden transitions in the Reflection-Infra-Red (RIR) Spectrum of footballene and of adamantane", C.R. Acad. Sci. Paris vol. 315 Série II, pp. 1653-1659, 1992.

31. T. Pichler, R. Winkler and H. Kuzmany, "Equilibrium phases in K- and Rb-doped $\mathrm{C}_{60}$ from in situ infrared reflectivity measurements", Phys. Rev. B vol. 49, pp. 15879-15889, 1994.

32. A. Peremans, Y. Caudano, P. A. Thiry, P. Dumas, W. Q. Zhang, A. Le Rille, and A. Tadjeddine, "Electronic Tuning of Dynamical Charge Transfer at an Interface: K Doping of $\mathrm{C}_{60} \mathrm{Ag}(111)$ ", Phys. Rev. Lett. vol.78, pp. 2999-3002, 1997.

33. See for example S. Modesti, J. K. Gimzewski, R. R. Schlittler, "Stable and metastable reconstructions at the $\mathrm{C}_{60} / \mathrm{Au}(110)$ interface", Surf. Sci. vol.331-331, pp. 1129-1135, 1995, and references therein.

34 S. Modesti, S. Cerasari and P. Rudolf, "Determination of Charge States of C.60 Adsorbed on Metal Surfaces", Phys. Rev. Lett. vol. 71, pp. 2469-2472, 1993.

35. J. E. Reutt, Y. J. Chabal and S. B. Christman, "Coupling of $\mathrm{H}$ vibration to substrate electronic states in $\mathrm{Mo}(100)-\mathrm{p}(1 \mathrm{x} 1) \mathrm{H}$ and $\mathrm{W}(100)-\mathrm{p}(1 \mathrm{x} 1) \mathrm{H}$ : Example of strong breakdown of adiabaticity", Phys. Rev. $B$ vol. 38 , pp. 3112-3131, 1988. 